\title{
reviews
}

\section{Triangle of parallel ideas}

Leibniz in Paris 1672-1676: His Growth to Mathematical Maturity. By Joseph E. Hofmann. Pp. xi+372. (Cambridge University: London, June 1974.) £8.50.

When Leibniz arrived in Paris in March 1672 as the travelling companion of Melchior Friedrich von Schönborn he knew little of the mathematics of the time. But under the guidance of Huygens he made rapid progress and over the next four years conceived his decisive ideas in mathematics, bringing them to a degree of completeness that allows us to see all his later research as elaboration and development. Leibniz would have liked to remain permanently in Paris but having failed to obtain a post there he reluctantly moved to Hanover in October 1676, where he took charge of the Library. It is a testimony to his irrepressible optimism that despite the uncertainty regarding his future Leibniz succeeded, during his last year in Paris, in attaining his greatest mathematical achievement: the invention of the calculus.

Professor Hofmann's brilliant account of these fruitful years in Paris, originally published as Die Entwichlungsgeschichte Leibnizschen Mathematik während des Aufenthalts in Paris (16721676), is now presented in a new version, carefully revised by the author and competently translated by A. Prag and D. T. Whiteside. The story is told with the thoroughness, meticulous documentation and clarity of exposition we have come to expect from the lamented master in the field of Leibnizian mathematics. There are three indexes. The first is a chronological index giving a register of all letters or original publications in contemporary periodicals mentioned in the text or footnotes, locations of manuscripts, meetings of learned societies and a checklist of publications in the periodical literature of the time. This is followed by an index of names and works, and a good subject index.

Leibniz's first mathematical discovery in Paris, concerning the summation of infinite series, illustrates two important characteristics of his work, namely the role played by considerations of logic and his preference for methods rather

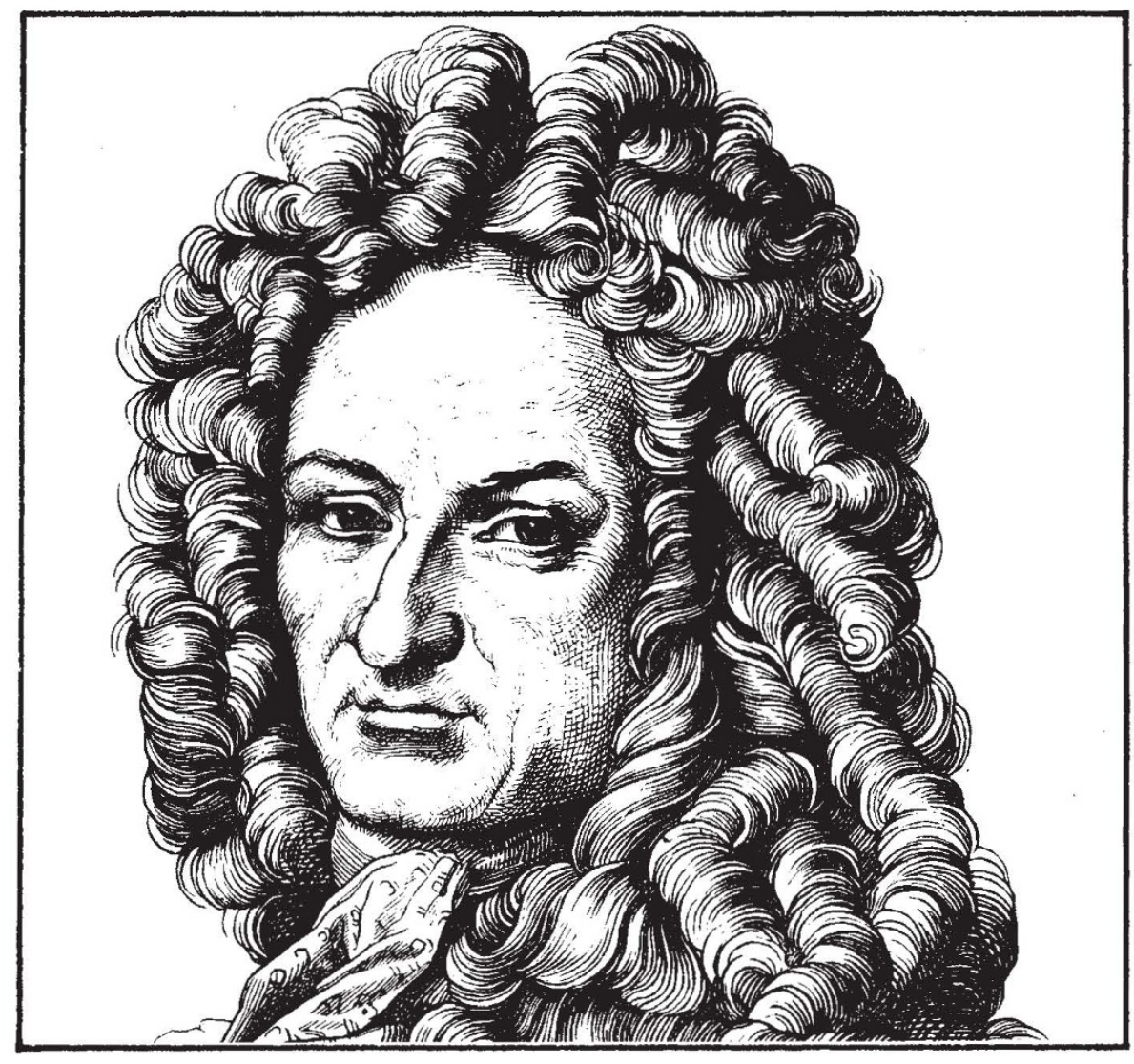

Gottfried Wilhelm von Leibniz-did not borrow from Newton

than results. Beginning simply with definitions and the axiom of identity, Leibniz obtained from Grégoire de Saint-Vincent's geometrical progression a general method which enabled him to sum the series of reciprocal triangular numbers, a problem proposed to him by Huygens.

Soon after his arrival in Paris, Leibniz made his first visit to London. Although this was not an unqualified success, it marked the beginning of the exchanges with English mathematicians which led eventually to the priority dispute concerning the invention of the calculus. Having appropriated Sluse's tangent rufe, Newton maintained that it was the communication of this rule in his own letter that led Leibniz to develop the ideas of the differential calculus. Leibniz always insisted that he had the rule from Sluse, and an excerpt from Sluse's treatise among his papers confirms the truth of this claim. Hofmann effectively demolishes the idea-unquestioned since the suggestion of Tschirnhaus in 1678-of a link between the ideas of Leibniz and those of Barrow. It was not from
Barrow and Newton but from Huygens, Grégoire de Saint-Vincent, Mercator, Gregory and Sluse that Leibniz received his inspiration. When Leibniz met Tschirnhaus towards the end of November 1675 , he already possessed his notation for the infinitesimal calculus. It is clear that Tschirnhaus, who had just visited London, could not have transmitted accurate reports of English mathematical methods to Leibniz (even if he had been told anything in detail) for, as his subsequent correspondence shows, he had not really penetrated to any fundamental level of mathematical understanding.

On the documentary evidence so skilfully presented and analysed in this volume, it is clear that Leibniz had truth on his side when he stressed that, as far as methods were concerned, he got nothing from the English. Hofmann's conclusion seems eminently fair: each of the three rivals (Newton, Leibniz and Gregory) achieved his own method; none borrowed or took over, from either of the others, more than certain incidental details.

E. J. Aiton 